\title{
High-Capacitance Supercapacitors Using Nitrogen-Decorated Porous Carbon Derived from Novolac Resin Containing Peptide Linkage
}

Yong Jung Kim ${ }^{1}$, In Young Jang ${ }^{2}$, Ki Chul Park ${ }^{2}$, Yong Chae Jung ${ }^{2}$, Takuyuki Oka ${ }^{2}$, Satoshi Iinou ${ }^{3}$, Yasuhiro Komori ${ }^{4}$, Toshihiko Kozutsumi ${ }^{4}$, Takashi Hashiba ${ }^{4}$, Yoong Ahm Kim $^{2} *$, Morinobu Endo ${ }^{1,2}$

${ }^{1}$ Institute of Carbon Science \& Technology, Shinshu University, 4-17-1 Wakasato, Nagano 380-8553 (Japan)

${ }^{2}$ Department of Electric and Electronic Engineering, Faculty of Engineering, Shinshu University, 4-17-1 Wakasato, Nagano 380-8553 (Japan)

${ }^{3}$ MEFS, Co. Ltd. Choei Nagano, Higasiguchi Bldg, 2F, 1000-1 Gentakubo, Kurita, Nagano 380-0921(Japan)

4 SHOWA HIGHPOLYMER, Co., Ltd. 1021 Tomizuka-cho, Isesaki-city, Gunma 372-0833 (Japan)

*Corresponding author: yak@endomoribu.shinshu-u.ac.jp; Tel: +81-26-269-5212, Fax: +81-26-269-5208

\begin{abstract}
We fabricated nitrogen-decorated porous carbon exhibiting high capacitance per unit volume and unit weight via chemical activation of novolac resin containing peptide linkage. The porosity and the amount of nitrogen atoms were controlled by changing the molecular weight of novolac resin, the added amount of potassium hydroxide, or both. After chemical activation, positively charged nitrogen atoms (i.e., pyridone/pyrrole) at $400.3 \mathrm{eV}$ in photoemission spectra contributed to both a shift in the point of zero charge toward negative potential and the generation of pseudocapacitance. Suitably developed pores and the positively charged nitrogen atoms make nitrogen-decorated novolac resin-derived porous carbon a promising material for electrodes in high-performance supercapacitors.
\end{abstract}

Keywords: Porous carbon, Novolac resin, Nitrogen atom, Porosity, X-ray photoemission spectroscopy, Capacitance 


\section{Introduction}

Extensive research has been carried out on supercapacitors, which are attractive energy storage devices due to their higher power density and higher efficiency compared with lithium-ion batteries [1]. The performance characteristics of supercapacitors are strongly dependent on the physical properties of the electrode material, and conventional and nano-sized porous carbons with high specific surface area have been examined as possible candidates for realizing high gravimetric capacitance [2-11]. However, for practical use of a supercapacitor within a limited space, for example, as an energy source for mobile devices and electric vehicles, it is necessary to consider energy density per unit volume. From the viewpoint of volumetric capacitance, conventional activated carbons are advantageous over low-density nanostructured carbons for fabricating high-density electrodes to realize supercapacitors with high specific energy. On the other hand, to improve the capacitive performance of supercapacitors, various heteroatoms (e.g., nitrogen, boron, oxygen, and phosphorous) have been introduced into porous carbons [12-18]. In particular, nitrogen atoms in porous carbons are known to contribute to the generation of pseudocapacitance.

In order to achieve high volumetric capacitance using nitrogen-decorated porous electrode, we prepared a novel type of novolac resin containing peptide linkage, and then prepared nitrogen-decorated porous carbon by activating the polymer with potassium hydroxide. We found that after chemical activation, the positively charged nitrogen atoms (i.e., pyridine/pyrrole) at $400.3 \mathrm{eV}$ in photoemission spectra contributed to both a shift in the point of zero charge toward positive potential and the generation of pseudocapacitance. Novolac resin-derived porous carbon exhibiting volumetric capacitance of $38.4 \mathrm{~F} / \mathrm{cc}$ at high current density of $60 \mathrm{~mA} / \mathrm{cm}^{2}$ in aprotic organic electrolyte is a promising material for electrode materials in supercapacitors.

\section{Experimental}

In this study, a novel novolac resin (containing peptide linkage) having molecular weight of 2000, 2500, and 4000 was prepared by polymerizing phenol and formaldehyde monomers, as shown in Fig. 1. More specifically, phenol (94 g, 1 mole), $37 \%$ formalin solution (56.8 g, 0.7 mole), oxalic acid (0.54 g, 0.006 mole) were used for synthesis of novolac resin having molecular weight of 4000. All reactants in a 500 
$\mathrm{ml}$ reactor equipped with a mechanical stirrer and a reflux condenser were reacted at $100{ }^{\circ} \mathrm{C}$ for $8 \mathrm{hrs}$. After the removal of water and unreacted formaldehyde (below 100 ppm) in a reactor, we have prepared novolac-type phenol resin having molecular weight of 4000 (ca. $80 \mathrm{~g}$ ). Then, novolac-type phenol resin having molecular weight of 4000 (80 g), methyl ethyl ketone (40 g), N-Methylolacrylamide (60.8 g) and oxalic acid (0.8 g) were reacted at $100{ }^{\circ} \mathrm{C}$ for $8 \mathrm{hrs}$. When the polymerization was over, impurities were effectively removed by washing with distilled water $(120 \mathrm{~g})$ four times. Finally, the previously prepared un-crosslinked form of a novolac resin was solidified (or cross linked) by adding both hexamethyleneamine and organic peroxide at $120{ }^{\circ} \mathrm{C}$, novel novolac-type phenol resin containing peptide linkage was synthesized.

The synthesized resin was thermally treated at $600{ }^{\circ} \mathrm{C}$ for $1 \mathrm{~h}$ in an argon atmosphere and then chemically activated with potassium hydroxide at $800{ }^{\circ} \mathrm{C}$ for $1 \mathrm{~h}$ under argon flow in order to generate pores for storing charge. After being washed several times with hydrochloric acid and deionized water, and dried under a vacuum, the obtained porous carbons were structurally characterized.

We conducted thermogravimetric analysis of the novolac resins using a Themoplus TG8120 (Rigaku, Japan) under argon flow (heating rate $=10{ }^{\circ} \mathrm{C} / \mathrm{min}$ ). The pore structure of all samples was confirmed by nitrogen adsorption at $77 \mathrm{~K}$ (ASAP2020, Micromeritics, USA). The elemental composition and chemical state of nitrogen atoms were investigated by X-ray photoelectron spectroscopy (XPS) performed on a JEOL JPS-9200 with a standard $\mathrm{Mg} \mathrm{K} \mathrm{K}_{\alpha}(1256.6 \mathrm{eV})$ X-ray source operated at $10 \mathrm{~mA}$ and 15 $\mathrm{kV}$. The entire spectrum was referenced to the $\mathrm{C} 1 \mathrm{~s}$ peak of graphite $(284.6 \mathrm{eV})$.

For electrochemical measurements, we mainly used a two-electrode system. Sheet-type electrodes with thickness of $0.4 \mathrm{~mm}$ were prepared with polytetrafluoroethylene ( $5 \mathrm{wt} \%$ ) as a binder, and a Pt plate and non-woven fabric were used as the current collector and separator, respectively. For all measurements, $1 \mathrm{M}$ tetraethylammonium tetrafluoroborate $\left(\left(\mathrm{C}_{2} \mathrm{H}_{5}\right)_{4} \mathrm{NBF}_{4}\right)$ in propylene carbonate was used as the electrolyte. Charge and discharge cycles were performed at constant current-constant voltage, and the capacitance was obtained from the variation in the current density of the discharge. Cyclic voltammetry (CV) and electrochemical impedance spectroscopy (EIS) were performed on a PARSTAT 2273 (Princeton Applied Research, USA). CV measurement was conducted at a scan rate of $1 \mathrm{mV} / \mathrm{s}$ in the range 
of $2.5 \mathrm{~V}$, and a silver wire was used as a quasi-reference electrode in a three-electrode cell. Impedance was measured in the frequency range from $1 \mathrm{mHz}$ to $100 \mathrm{kHz}$ by applying $10 \mathrm{mV}$ of the potential amplitude. Electrochemical measurements in organic electrolyte were carried out in an argon-filled glove box at room temperature.

\section{Results and discussion}

The novolac resin was prepared by polymerization of formaldehyde and phenol monomers with $\mathrm{N}$-methyl acrylamide (NMAA) as an additive (Fig. 2(a)); the nitrogen functionality (peptide linkage) was introduced via the condensation reaction between phenol and NMAA. NMAA was added in the range of 40-150 molecules for every 100 hydroxyl groups of the phenol moieties. The NMAA was introduced to the ortho- and para-positions of the repeating phenolic monomer units. A light-brown (inset in Fig. 2(a)) novolac resin containing about $7.8 \mathrm{wt} \%$ nitrogen atoms was obtained. When the novolac resin was thermally treated up to $1000{ }^{\circ} \mathrm{C}$ in argon (Fig. 2(b)), a rapid decrease in weight was observed in the temperature range of $300-400{ }^{\circ} \mathrm{C}$, and the carbonization yield at $600{ }^{\circ} \mathrm{C}$ was found to be approximately $42 \%$. The carbonized resin had a plate-like micro-morphology (Fig. 2(c)) and formed black granules (see inset in Fig. 2(c)). We selected potassium hydroxide as the reagent for generating pores (i.e., increasing the specific surface area). We prepared nitrogen-decorated, relatively high-density porous carbon (Fig. 2(d)) by thermally treating a mixture of the carbonized resin and a specific amount of potassium hydroxide at $900{ }^{\circ} \mathrm{C}$ in $\operatorname{argon}$.

The effectiveness of potassium hydroxide as a chemical activating agent (or pore creating agent) was clearly confirmed by the 8 - to 9-fold increase in the specific surface area of the novolac resin-derived porous carbon (see Table 1). Interestingly, we observed that the specific surface area of the porous carbon monotonically increased with increasing molecular weight of the novolac resin or the added amount of potassium hydroxide. The specific surface area of the porous carbon that was prepared by activating novolac resin having molecular weight of 4000 with 400 wt \% potassium hydroxide reached ca. $3000 \mathrm{~m}^{2} / \mathrm{g}$. It is noteworthy that the capacitive behavior of the porous carbon was determined by not only the specific surface area, but also the porosity (i.e., pore size and distribution). For example, micropores with diameters of about $0.5-1.0 \mathrm{~nm}$ are well known to be accessible to aqueous and non-aqueous 
electrolyte ions $[19,20]$. As listed in Table 1, the porous carbon that was prepared by activating novolac resin with $250 \mathrm{wt} \%$ potassium hydroxide exhibited the highest gravimetric and volumetric capacitances both at low and high current densities, owing to the optimally generated pore size and distribution.

Next, the nitrogen atoms remaining in the porous carbon should be considered, as we used nitrogen-containing polymer as a precursor to the porous carbon. In order to observe the differences between nitrogen species, we carried out XPS studies on the novolac resin-derived porous carbon. Novolac resin that was thermally treated at $600{ }^{\circ} \mathrm{C}$ for $1 \mathrm{~h}$ in argon exhibited two peaks at 399.4 and $400.3 \mathrm{eV}$ in the N1s spectrum (Fig. 3) $[21,22]$; the former corresponds to neutral amine, while the latter corresponds to the positively charged nitrogen atoms of pyridine/pyrrole. After chemical activation with 200 wt $\%$ potassium hydroxide, the amount of remaining nitrogen atoms was reduced from 2.28 to 0.82 atom $\%$. Notably, the main nitrogen species in the chemically activated novolac resin-derived porous carbon were the charged nitrogen atoms of pyridine/pyrrole.

Finally, in order to evaluate the applicability of novolac resin-derived porous carbon as an electrode material for supercapacitors, as well as to understand the effects of the nitrogen species on the capacitive behavior, we carried out detailed electrochemical studies on the novolac resin-derived porous carbon through a direct comparison with commercially available porous carbons containing no nitrogen moiety (Fig. 4). For the commercially available samples, we selected porous carbons derived from phenol resin and coconut shells, which were supplied by Kuraray Chemical Co. and Kansai Coke and Chemical Co. Ltd., respectively. CV curves obtained using the two-electrode system exhibited ideal rectangular profiles (Fig. 4(a)), while those obtained using the three-electrode system clearly deviated from an ideal rectangular shape (Fig. 4(b)). In addition, we observed a downward shift in the potential of zero charge for the prepared novolac resin-derived porous carbon, owing to the nitrogen species decorating the outer surface. As shown by the XPS study (Fig. 3), the nitrogen atoms in quaternary and oxidized forms have positive charge. More specifically, pyridine/pyrrole-like nitrogen species induced high positive charge densities on adjacent carbon atoms [21, 22]. Thus, the deviation of the CV curves from the ideal shape appeared to be attributable to pseudocapacitance based on Faradic reactions. Overall, 
the novolac resin-derived porous carbon exhibited better capacitive behavior than the commercially available porous carbons. The specific energy and power density of the material were $38.5 \mathrm{Wh} / \mathrm{kg}$ and $18.74 \mathrm{Wh} / \mathrm{L}$, respectively. Furthermore, we measured ac impedance spectra (Nyquist plot) (Fig. 4(c)) for all samples. This plot consists of 3 main regions [23]; (I) a semicircular arc representing the resistance and capacitance of the contact between electrode and current collector, and the resistance of porous electrode itself, (II) an inclined line corresponding to the diffusion of electrolyte ions within pores of carbon, and (III) straight line at low frequency indicating blocking electrode behavior. When considering the resistance of capacitor, the internal resistance of New PF resin electrode was smaller than that of coconut shell electrode, but higher than that of the PF resin electrode. This impedance behavior is ascribed to the high fraction of micropore volume in New PF resin electrode because of the bad accessibility of ions toward micropore. Although the mechanism of pseudocapacitive interactions between ions and nitrogen atoms is not clear, moreover, the large semicircle in Nyquist plot was reported to be associated with the faradic pseudocapacitive interaction in an aprotic electrolyte [13].

\section{Conclusions}

We have fabricated nitrogen-decorated porous carbon through chemical activation of newly prepared novolac resin containing peptide linkage. We then evaluated the suitability of the electrode material for use in a supercapacitor through direct comparison with commercially available porous carbons. We found that the pore parameters were strongly dependent on the molecular weight of the novolac resin and the added amount of potassium hydroxide. More importantly, positively charged nitrogen species remained on the surface of the porous carbon after the chemical activation process. As a result, porous carbon exhibiting optimal gravimetric and volumetric capacitances could be prepared by activating novolac resin having molecular weight of 4,000 with $250 \mathrm{wt} \%$ potassium hydroxide at $900{ }^{\circ} \mathrm{C}$ in argon. This nitrogen-decorated novolac resin-derived porous carbon is thought to be a promising candidate material for electrodes in supercapacitors.

\section{Acknowledgements}


This work was in part supported by the CLUSTER (second stage) and MEXT grants (Nos. 19002007 and 20510096), Japan. 


\section{References}

[1] B.E. Conway, Electrochemical Supercapacitors, Scientific Fundamentals and Technological Applications, Kluwer Academic/Plenum Press, New York, 1999.

[2] J. R. Miller, P. Simon P. Science 321 (2008) 651.

[3] K. H. An, W. S. Kim, Y. S. Park, J.-M. Moon, D. J. Bae, S. C. Lim, Y. S. Lee, Y. H. Lee, Adv. Funct. Mater. 11 (2001) 387.

[4] K. H. An, W. S. Kim, Y. S. Park, Y. C. Choi, S. M. Lee, D. C. Chung, D. J. Bae, S. C. Lim, Y. H. Lee, Adv. Mater. 13 (2001) 497.

[5] E. Frackowiak, F. Béguin, Carbon 39 (2001) 937.

[6] A. B. Fuertes, G. Lota, T. A. Centeno, F. Frackowiak, Electrochim. Acta. 50 (2005) 2799 .

[7] C. M. Yang, Y. J. Kim, M. Endo, H. Kanoh, M. Yudasaka, S. Iijima, K. Kaneko, J. Am. Chem. Soc. 129 (2007) 20.

[8] Y. J. Kim, Y. A. Kim, T. Chino, H. Suezaki, M. Endo, M. S. Dresselhaus, Small 2 (2006) 339.

[9] M. Endo, T. Maeda, T. Takeda, Y. J. Kim, K. Koshiba, H. Hara, M. S. Dresselhaus, J. Electrochem. Soc. 148 (2001) A910.

[10]C. Kim, B. Thi Nhu Ngoc, K.S. Yang, M. Kojima, Y. A. Kim, Y. J. Kim, M. Endo, Adv. Mater. 19 (2007) 2341.

[11]L. Cooper, H. Amano, M. Hiraide, S. Houkyou, I. Y. Jang, Y. J. Kim, H. Muramatsu, J. H. Kim, T. Hayashi, Y. A. Kim, M. Endo, M. S. Dresselhaus, Appl. Phys. Lett. 95 (2009) 233104.

[12] G. Lota, B. Grzyb B, H. Machnikowska, J. Machnikowski, E. Frackowiak, Chem. Phys. Lett. 404 (2005) 53.

[13]D. Hulicova, M. Kodama, H. Hatori, Chem. Mater. 18 (2006) 2318.

[14]D. Hulicova, J. Yamashita, Y. Soneda, H. Hatori, M. Kodama, Chem. Mater. 17 (2005) 1241.

[15] K. Jurewicz, K. Babel, A. Zilokowski, H. Wachowska, Electrochim. Acta 48 (2003) 1491.

[16]E. Raymundo-Piñero, D. Cazorla-Amoros, A. Linares-Solano, J. Find, U. Wild, R, Schlogl, Carbon 40 (2003) 597. 
[17]E. Raymundo-Piñero, F. Leroux, F. Béguin, Adv. Mater. 18 (2006) 1877.

[18] T. Kwon, H. Nishihara, H. Itoi, Q. Hi. Yang, T. Kyotani, Langmuir, 25 (2009) 11961.

[19] J. Chmiola, G. Yushin, Y. Gogotsi, C. Portet, P. Simon, P. L. Taberna, Science 313 (2006) 1760.

[20]E. Raymundo-Piñero, K. Kierzek, J. Machnikowski, F. Béguin, Carbon 44 (2006) 2498.

[21] S. R. Kelemen, M. L. Gorbaty, P. J. Kwiatek, Energy \& Fuels 8 (1994) 896.

[22]J. R. Pels, F. Kapteijin, J. A. Moulijin, Q. Zhu, K. M. Thomas, Carbon 33 (1995) 1641.

[23] S. Zhao, C.Y. Wang, M.M. Chen, J. Wang and Z.Q. Shi, J. Phys. Chem. Solids 70 (2009) 1256. 


\section{Figure Captions}

Figure 1. A schematic diagram of the experimental procedure for synthesizing novolac-type phenolic resin containing peptide linkage.

Figure 2. (a) Molecular structure of novolac resin containing peptide linkage (inset is photograph of light-brown polymerized novolac resin), (b) thermogravimetric analysis of novolac resin up to $1000{ }^{\circ} \mathrm{C}$ in argon (heating rate $=10{ }^{\circ} \mathrm{C} / \mathrm{min}$ ), (c) SEM image showing micro-sized quasi-rectangular morphology, and (d) TEM image showing porous structure.

Figure 3. XPS N1s spectrum of novolac resin thermally treated at $600{ }^{\circ} \mathrm{C}$ in argon and potassium hydroxide-activated porous carbon. Note that the positively charged nitrogen atoms of pyridine/pyrrole at $400.3 \mathrm{eV}$ are present mainly on the porous carbon.

Figure 4. Detailed electrochemical studies of novolac resin-derived porous carbon were carried out through direct comparison with two commercially available porous carbons (phenol resin-derived porous carbon and coconut shell-derived porous carbon) using cyclic voltammograms obtained from (a) a two-electrode system and (b) a three-electrode system, and (c) comparative Nyquist plots (as signal level is $10 \mathrm{mV}$; frequency range is $1 \mathrm{mHz}$ to $100 \mathrm{kHz}$ ). 


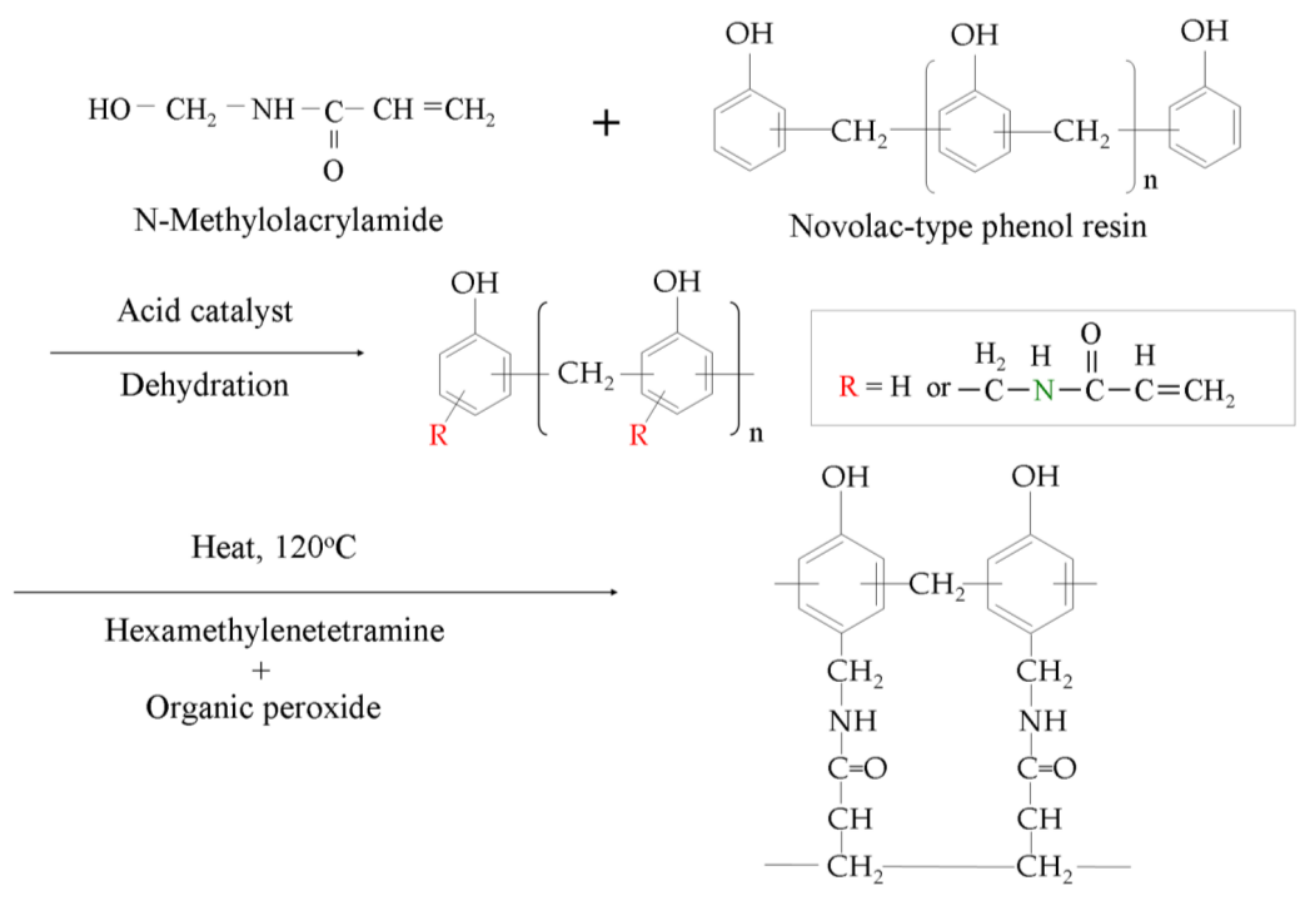

Novolac-type phenol resin containing peptide linkage

Figure 1

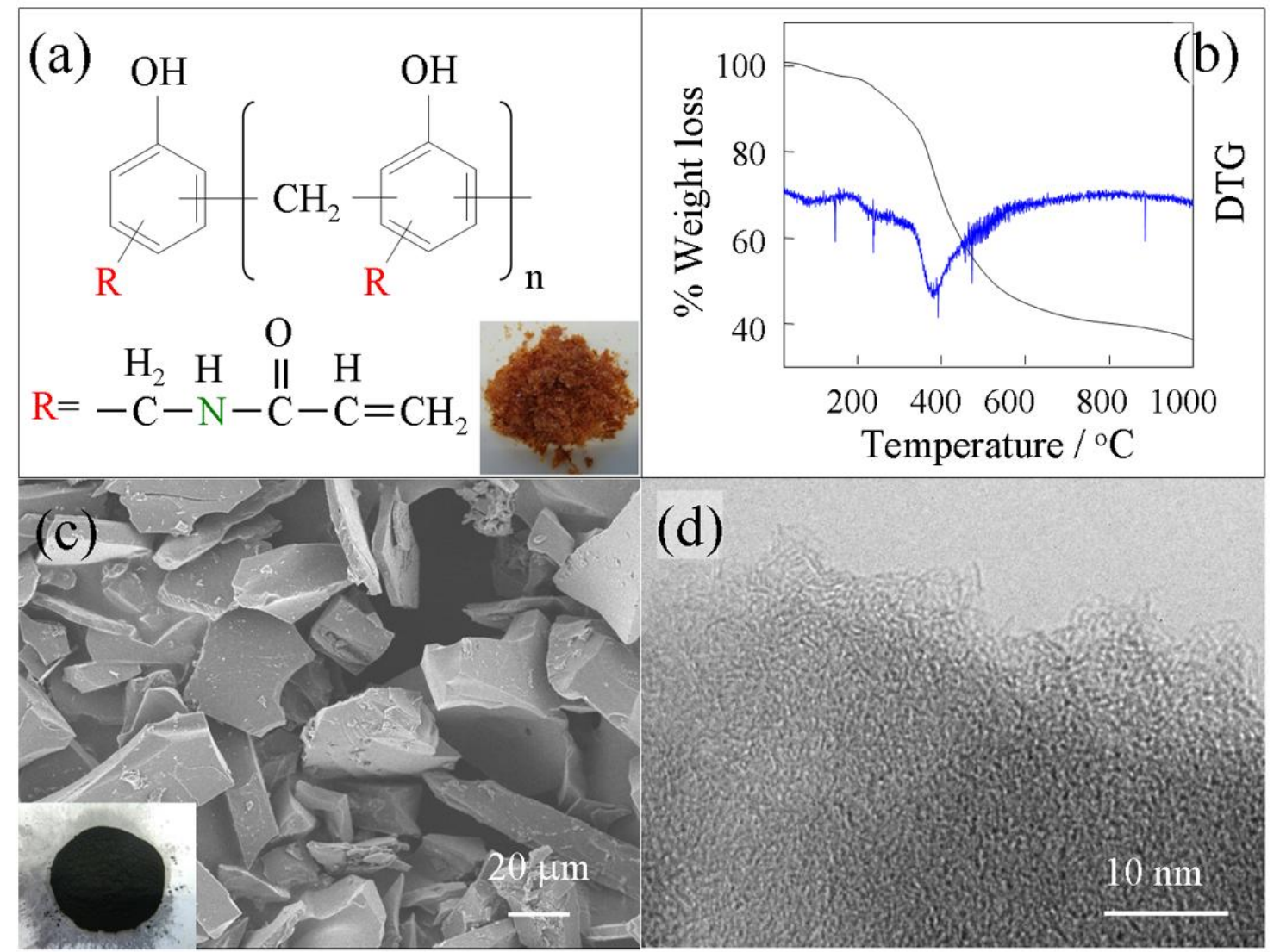

Figure 2 


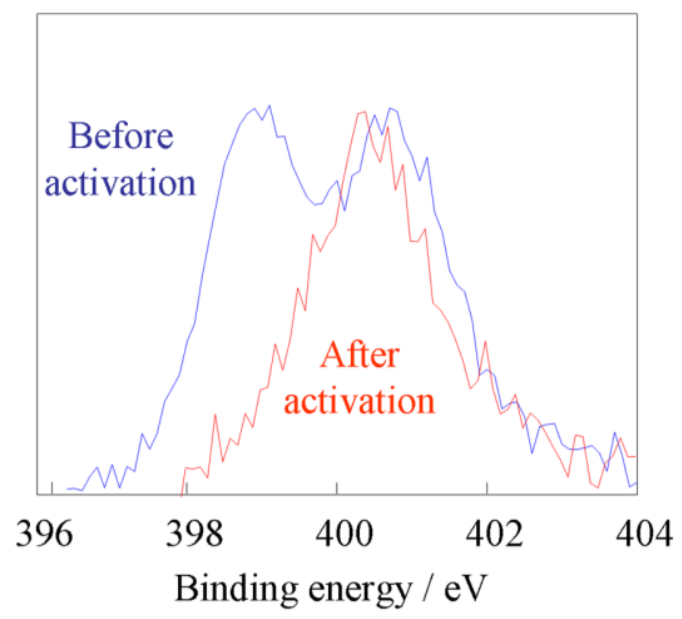

Figure 3
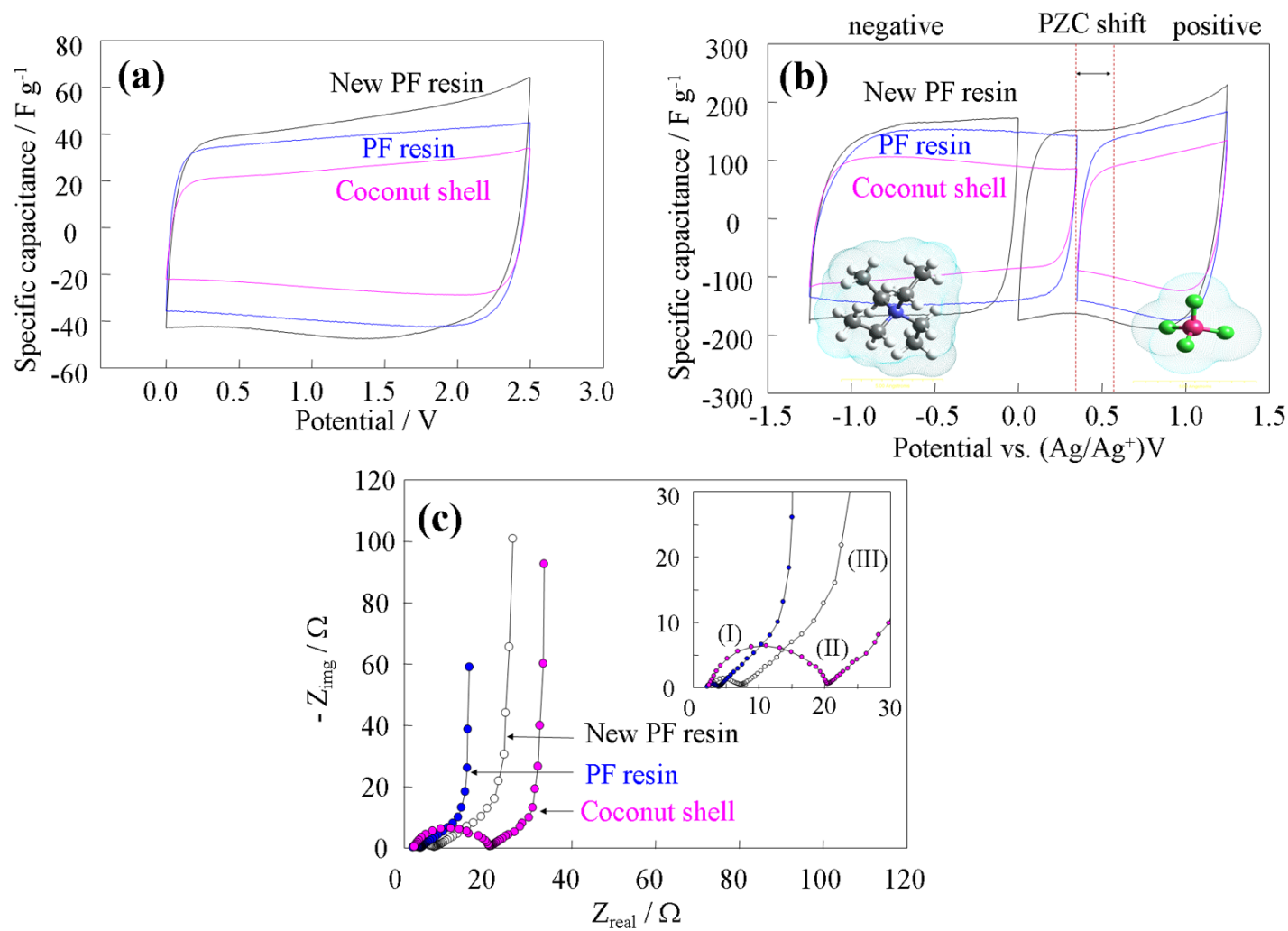

Figure 4 
Table 1 Pore structure and capacitance of novolac resin-derived porous carbon as a function of molecular weight of novolac resin and the added amount of potassium hydroxide. For comparison, we have added pore structure and capacitance of coconut shell- and phenol resin-derived porous carbons.

\begin{tabular}{|c|c|c|c|c|c|c|c|c|}
\hline \multirow{2}{*}{ M.W. ${ }^{a}$} & \multirow{2}{*}{$\mathrm{KOH} / \mathrm{wt} \%$} & \multicolumn{3}{|c|}{ Pore structure ${ }^{c}$} & \multicolumn{2}{|c|}{$\begin{array}{l}\text { Gravimetric capacitance } \\
\qquad / \mathrm{F} \mathrm{g}^{-1 \mathrm{~g}}\end{array}$} & \multicolumn{2}{|c|}{$\begin{array}{c}\text { Volumetric capacitance } \\
\qquad / \mathrm{F} \mathrm{cc}^{-1 \mathrm{~g}}\end{array}$} \\
\hline & & $\mathrm{SSA} / \mathrm{m}^{2} \mathrm{~g}^{-1 \mathrm{~d}}$ & $\mathrm{~V}_{\text {micro }} / \mathrm{cm}^{3} \mathrm{~g}^{-1 \mathrm{e}}$ & $\mathrm{APD} / \mathrm{nm}^{\mathrm{f}}$ & $1 \mathrm{mAcm}^{-2}$ & $60 \mathrm{~mA} \mathrm{~cm}^{-2}$ & $1 \mathrm{~mA} \mathrm{~cm}^{-2}$ & $60 \mathrm{~mA} \mathrm{~cm}^{-2}$ \\
\hline 4000 & 0 & 271 & 0.095 & 1.30 & 0.4 & - & 0.4 & - \\
\hline 1000 & 200 & 2310 & 0.793 & 1.59 & 135.2 & 26.3 & 86.8 & 16.9 \\
\hline 2500 & 200 & 2325 & 0.795 & 1.61 & 174.0 & 24.4 & 105.6 & 14.8 \\
\hline 4000 & 200 & 2440 & 0.842 & 1.61 & 176.8 & 25.2 & 104.8 & 14.8 \\
\hline 4000 & 250 & 2679 & 0.953 & 1.71 & 180.4 & 70.8 & 98.4 & 38.4 \\
\hline 4000 & 400 & 2954 & 1.163 & 2.03 & 158.8 & 49.2 & 70.4 & 22.0 \\
\hline \multicolumn{2}{|c|}{ Coconut shell } & 1508 & 0.514 & 1.89 & 81.9 & 10.9 & 48.3 & 8.7 \\
\hline \multicolumn{2}{|c|}{$\mathrm{PF}$ resin } & 2370 & 0.855 & 1.70 & 134.3 & 28.3 & 74.3 & 21.0 \\
\hline
\end{tabular}

\footnotetext{
${ }^{\mathrm{a}}$ M.W. denotes molecular weight of novolac resin. ${ }^{\mathrm{b}} \mathrm{KOH}$ denotes potassium hydroxide. ${ }^{\mathrm{c}}$ Pore parameters were obtained by measuring $\mathrm{N}_{2}$ adsorption.

${ }^{\mathrm{d}}$ SSA denotes specific surface area. ${ }^{\mathrm{e}} \mathrm{V}_{\text {micro }}$ denotes micropore volume. ${ }^{\mathrm{f}}$ APD denotes average pore diameter. ${ }^{\mathrm{g}}$ Capacitance values $(\times 4)$ were obtained using the two-electrode system.
} 